\title{
Sequencing of water supply options at the regional scale incorporating sustainability objectives
}

\author{
$\underline{\text { Eva H.Y Beh }}{ }^{\mathrm{a}}$, Graeme C. Dandy ${ }^{\mathrm{a}}$ and Holger R. Maier \\ ${ }^{a}$ School of Civil, Environmental and Mining Engineering, The University of Adelaide, Adelaide 5005 \\ Email: ebeh@civeng.adelaide.edu.au
}

\begin{abstract}
In recent years, urban water systems in Australia have faced potential shortages due to recurring drought and climate change. Moreover, increasing population is leading to increasing demand in urban centres. There are many alternatives for addressing this challenge, including utilisation of different water sources (e.g. desalination, rainwater, stormwater and greywater re-use) and implementation of different policy drivers (e.g. water pricing, water restrictions and rebates for water conservation measures). However, any of these options in isolation will not be sufficient to solve the problem and the choice of the optimal combination of these strategies is a difficult task. This problem is aggravated by the need to consider tradeoffs between multiple criteria, such as security of supply, cost, energy consumption, ecological impact, public health impacts and social acceptability. In response, a general approach is proposed to sequence water supply projects, incorporating sustainability, at the regional scale. Sequencing of water supply projects involves choosing which options to implement at which stage over a planning horizon. This allows projects to be introduced when they are needed, and reduces redundancy associated with the system. In the past, the sequencing of water supply projects was relatively straightforward, as there were relatively few options (e.g. when to build the next reservoir) and the only criteria that had to be considered were water supply security and cost. However, as a result of drought, climate change and the increased adoption of sustainability principles, the problem of sequencing water supply projects has become much more complex. With the increase in urbanisation and urban infill, there is an increase in the potential to use desalination and recycled water as alternative water supply options. Therefore, in addition to new reservoirs, a large number of alternative water sources are able to be considered in the sequencing approach presented in this paper. They include desalination, stormwater re-use and rainwater tanks. Furthermore, a range of different criteria, such as energy consumption and greenhouse gas (GHG) emissions are able to be taken into account in addition to economic and water supply security criteria to decide which combination of water supply options will perform best. The approach proposed involves predicting the yield of individual water supply options and selecting which combination of sources is best in terms of economic and environmental criteria and when certain sources should be developed and brought into operation at each decision stage over the planning horizon. The proposed approach is applied to the Southern Adelaide water supply system, which has various water supply options, to demonstrate its effectiveness and its ability to provide useful information for managers of the system. The approach is aimed at providing water authorities with a clearer view of the trade-offs between competing objectives of alternative combinations of water sources and hence guiding them towards a more sustainable approach to water resource management.
\end{abstract}

Keywords: Sequencing, Urban Water Management, Sustainability 
Beh et al., Sequencing of water supply options at the regional scale incorporating sustainability objectives

\section{INTRODUCTION}

The use of sequencing has long been adopted as a means of increasing water supply security and minimising water supply costs (Becker \& Yeh, 1974). In the past, this has been applied primarily to the expansion of multiple reservoirs (Braga et al., 1985; Dandy \& Connarty, 1994). However, in recent years, the reliability of traditional water supply sources has come under threat as a result of increasing demand and reduced reliability of supply due to climatic factors (Chartres \& Williams, 2006). In response, a number of alternative sources are being considered, including desalinated seawater, rainwater and the re-use of stormwater and greywater (Voivantas et al., 2003; Coombes \& Lucas, 2006; Eroksuz \& Rahman, 2010). This has resulted in an increase in the complexity of the sequencing problem, due to the larger number of potential water supply options that need to be considered, as well as the increased frequency at which projects need to be implemented due to the smaller capacities of localised sources of water, such as rainwater, stormwater and greywater. Another factor that has increased the complexity of the sequencing problem is the need to consider criteria other than economic cost in the evaluation of different sequencing plans (e.g. energy usage, greenhouse gas emissions etc.), as the need to develop sustainable water supply systems is becoming increasingly important (Gleick, 1998). Consequently, there is a need to develop a sequencing approach that takes into account alternative sources of water, shorter staging intervals and multiple objectives. Such an approach is presented in this paper and applied to southern portion of the water supply system for Adelaide, South Australia.

\section{PROPOSED SEQUENCING METHODOLOGY}

The sequencing process introduced in this paper involves subdividing the planning horizon into a finite number of stages. Within each staging interval, different water supply options are considered, examples of which are outlined in Figure 1. For each option, a set of capacities is considered (Figure 1), which means that during each staging interval, each supply option can be assigned a discrete capacity value ranging from the current capacity to the maximum possible capacity. A set of constraints is also identified for each stage, which is likely to be different at each of the stages because of changes in both demand and supply over time.

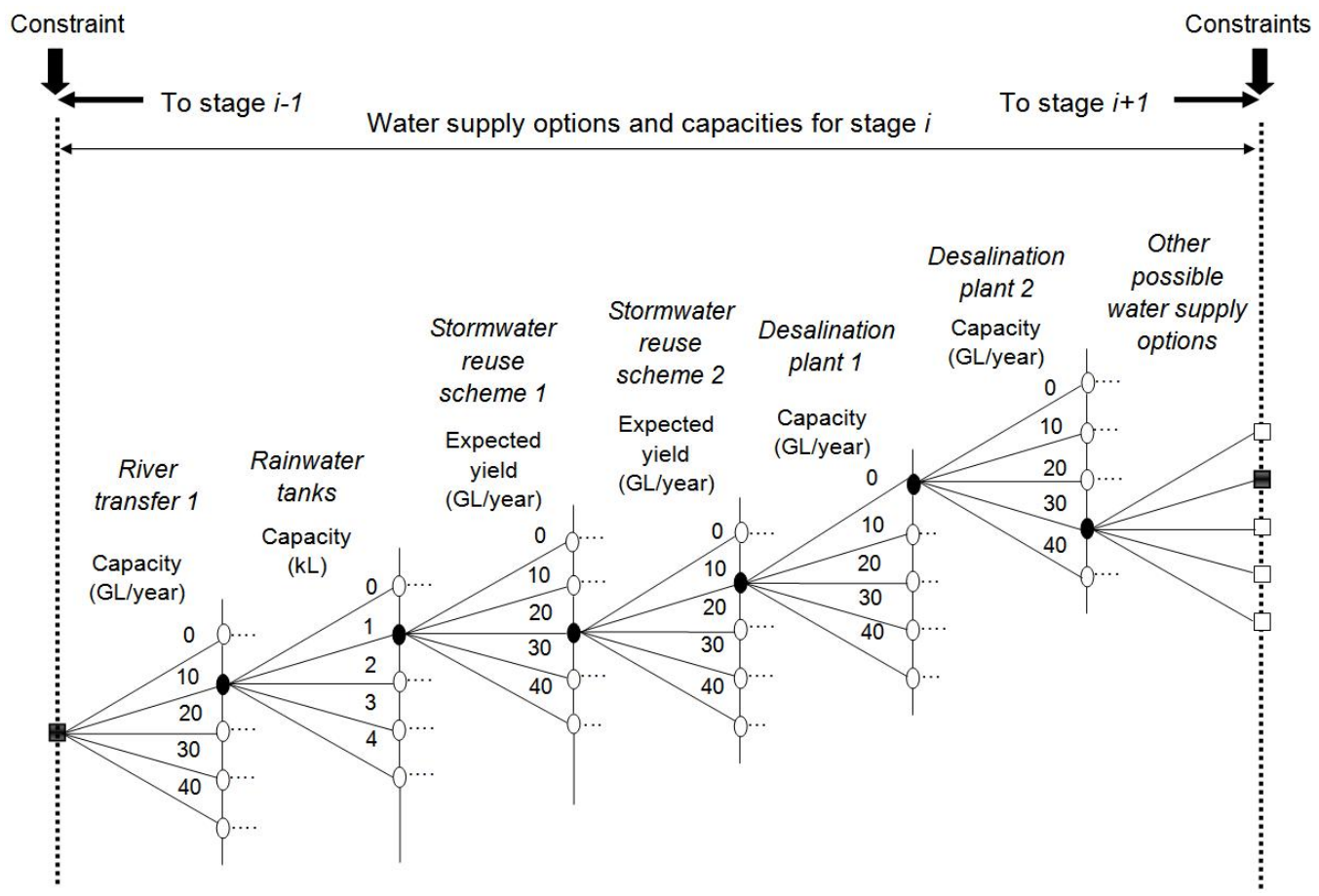

Figure 1 Flow diagram of one possible combination of water supply options with capacities selected at one decision point, $i$, in a water supply sequencing problem of $N$ stages 
Beh et al., Sequencing of water supply options at the regional scale incorporating sustainability objectives

The proposed sequencing approach consists of 3 major steps. The first step is the problem formulation, which includes setting the planning horizon and staging interval, selecting sustainability objectives and choosing potential water supply options. The next step is the calculation of the unit objective function value for possible water supply options, with the aim of determining the design yield and corresponding unit cost of each potential source. The third step is the sequencing process, during which the best combination of potential water supply options is selected.

In this paper, the proposed approach is demonstrated for the case study of the southern Adelaide water supply system, which supplies about half of the demand of metropolitan Adelaide. The system consists of 3 reservoirs: Mount Bold, Happy Valley and Myponga. In addition, there are transfers from the River Murray via the MurrayOnkaparinga pipeline, a desalination plant, which is currently under construction, existing and potential stormwater reuse schemes, and household rainwater tanks. Further details of the case study system are given in Paton et al. (2009).

\subsection{Problem Formulation}

In the problem formulation stage, three main issues related to water supply need to be identified, as shown in Error! Reference source not found.. One of these is selection of the water supply options, $S$, from which to draw a supply of water for consumers (see Figure 1). The supply could be rainfall dependent or independent (Figure 2). Common rainfall dependent sources, $S_{D}$ include reservoirs, stormwater re-use, groundwater and rainwater tanks. Examples of rainfall independent sources, $S_{I N}$ are desalination plants and wastewater re-use schemes. For the case study, the rainfall dependent sources included water from the local catchments and stormwater and rainwater re-use. The rainfall independent sources included the desalination plant and transfers from the River Murray, which are governed by a licensing agreement. The license from the River Murray was taken as 30GL/year, which was terminated in 2025 in order to reduce Adelaide's reliance on River Murray water. In order to take account of the impact of climate variability, stochastic rainfall sequences need to be generated for the rainfall dependent sources. For the case study, 1000 sequences of 40 years of daily stochastic rainfall data for six rainfall sites within the demand area were generated using the Stochastic Climate Library (SCL) (www.toolkit.net.au/scl).

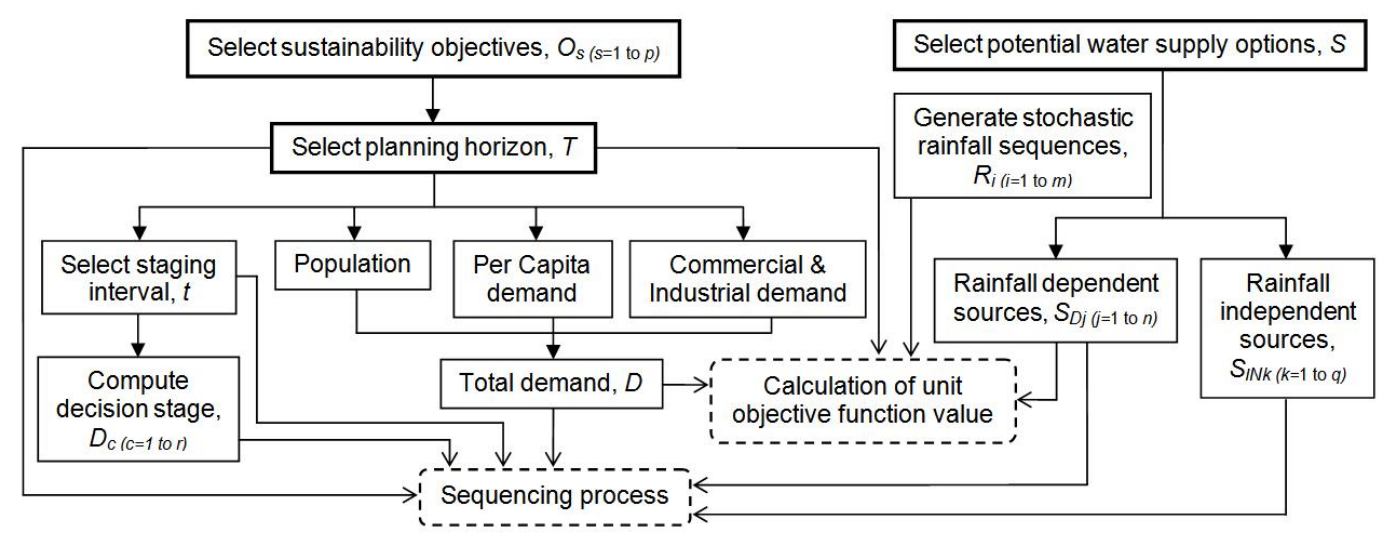

Figure 2 Problem formulation process

The next step in the proposed problem formulation process is the selection of appropriate sustainability objective(s), $O_{S}$ to be optimised during the development of the sequencing plans (Figure 2). For the case study, the selected objectives include economic cost and greenhouse gas (GHG) emissions from the construction and operation of the selected water supply options.

Next, the planning horizon, $T$, needs to be selected (Figure 2), which is 40 years for southern Adelaide system. At the same time, the staging interval, $t$, needs to be selected, which is the length of time between decision points in the sequencing plan. This interval needs to reflect a realistic period for the assessment of planning decisions and the design life of supply options. For the case study, a staging interval of five years was adopted, as the design life of system components is likely to be greater than five years, and this time period allows for the review of plans in light of changing system variables, such as rainfall and costs. Five years is also a practical period for review from a political perspective. After the planning horizon and staging interval have been defined, the 
Beh et al., Sequencing of water supply options at the regional scale incorporating sustainability objectives

number of decision stages, $D_{S}$ can be computed by dividing the planning horizon by the staging interval. At each decision stage, appropriate water supply options are defined, and the corresponding capacities are specified. The case study included eight decision stages over the 40 year planning horizon; and the constraint set at each decision stage was the supply must sufficiently meet the demand.

Of particular importance to decisions made at each stage is the estimation of total demand, $D$, which is a function of population size, per capita demand and commercial and industrial demand (Figure 2). For the case study, the population was estimated to be 597,000 for the southern Adelaide region, with an average population growth of $0.85 \%$ per year. Additionally, it was assumed that more people would live in high density dwellings (e.g. apartments and units) in the future, so that garden watering would be reduced as a percentage of total demand. Further demand reductions were assumed based on the adoption of water efficient household products, such as low flow showerheads, dual flush toilets and higher efficiency washing machines. Thus, the following future demands with projected reductions were used in the calculations:

1. $34.02 \mathrm{GL}$ per annum in-house residential use, such as drinking, bathing and laundry, with $0.39 \%$ annual reduction;

2. 34.02GL per annum in ex-house residential use, such as toilet flushing and garden watering, with $0.9 \%$ annual reduction;

3. $39.96 \mathrm{GL}$ per annum in commercial, industrial, recreation, public utilities and public institutions demand, with $0.47 \%$ annual reduction.

Supply from the three reservoirs and the desalination plant was chosen for meeting in-house residential demand; stormwater reuse was selected as the first option to supply industrial and commercial demand; and rainwater tanks were used for the supply of ex-house residential demand. The following capacity options for the potential water supply options were considered in the sequencing process:

- Desalination plant: 50GL and 100GL;

- Rainwater tanks: $1 \mathrm{~kL}, 2 \mathrm{~kL}, 5 \mathrm{~kL}, 10 \mathrm{~kL}$;

- Stormwater reuse schemes: See Section 2.2.

As shown in Figure 2, data from the problem formulation were used in the calculation of unit objective function values (Section 2.2) and in the sequencing process (Section 2.3).

\subsection{Calculation of Unit Objective Function Value for Possible Water Supply Options}

In order to develop the sequence plans, the most appropriate water supply options need to be selected at each decision stage. This is achieved by identifying the design yield and corresponding unit objective function value of each supply option, so that the "best" supply option(s) can be selected in accordance with the specified objectives. In order to be able to calculate the objective function value for each of the options, design yield is a key parameter. However, this is variable for the rainfall dependent sources due to climatic variability. Therefore, in order to obtain a single design yield, a distribution of likely yields should be generated based on the stochastic rainfall sequences (see Section 2.1), which can be used to obtain a distribution of likely yields for each source using a simulation model, from which a design yield with an appropriate exceedance probability can be selected. This process is shown in Error! Reference source not found.
For the case study, 1000 sequences of stochastic rainfall (see Section 2.1) were used to produce a distribution of 1000 predicted yields for the reservoirs, stormwater reuse schemes and rainwater tanks. Design yield was chosen based on the requirement that there was a $90 \%$ chance of the yield being achieved. The design yields of the stormwater reuse schemes were taken as their maximum capacity during the sequencing process. Consequently, the capacities adopted were 2.37GL/year (West zone), 10.51GL/year (South zone), and 7.00GL/year (Onkaparinga zone).

Next, the values of the sustainability objectives selected in the problem formulation step (i.e. total cost and GHG emissions for the case study considered) need to be calculated for each of the rainfall dependent sources. Finally, the unit objective function values need to be calculated by dividing the objective function values by the design yields. In this case study, calculation of cost and GHG emission were based on the method adopted 
Beh et al., Sequencing of water supply options at the regional scale incorporating sustainability objectives

in Paton et al. (2009). It should be noted that for the rainfall independent sources, $S_{I N}$ such as the desalination plant, unit objective function values can be calculated directly from the objective function values and the maximum expected capacity, as design yields are not subjected to climatic variation.

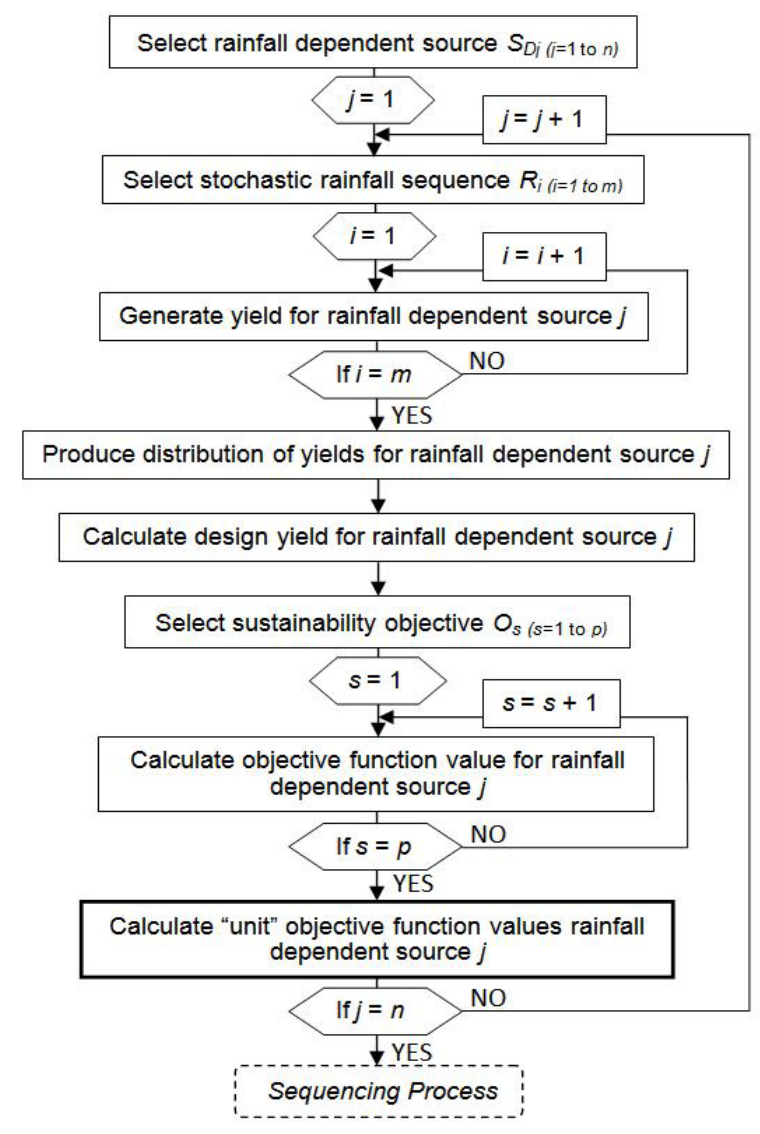

Figure 3 Calculation of unit objective function value for rainfall dependent sources.

\subsection{Sequencing Process}

The final step in the proposed process involves sequencing the potential water supply options along the planning horizon, $T$ by optimising the selected sustainability objective(s), $O_{S}$, at each decision stage, as shown in Figure 4. In the case study, economic cost was selected for optimisation in the sequence plan. However, GHG emissions could also have been selected as the objective for which to optimize, which would have resulted in a different sequencing plan. So, for the first decision stage $\left(D_{1}\right)$, the water supply option(s) with the lowest unit cost value should be introduced into the system. If the resulting predicted yield does not meet the projected demand, option(s) with the second lowest unit cost value need to be selected and so on until the total predicted yield from the combination of selected water supply options is sufficient to meet the projected demand. This step has to be repeated for all decision stages, forming a preliminary sequence plan. The preliminary sequence plan then needs to be assessed using a simulation model in order to check its feasibility, which the supply meets demand throughout the planning horizon.

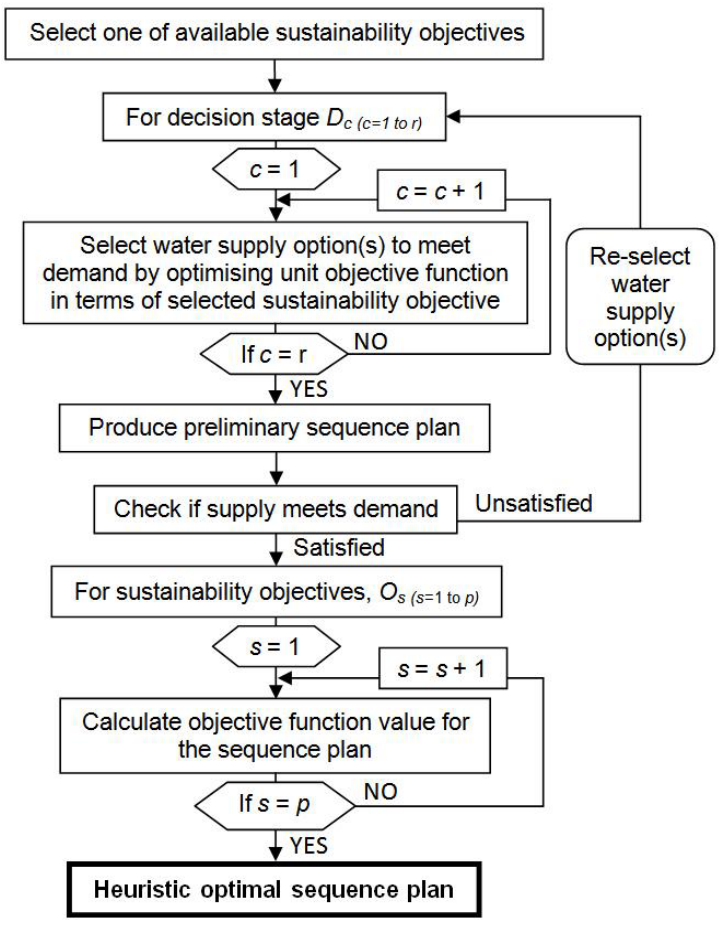

Figure 4 Proposed sequencing process

For the case study, WaterCress (Water-Community Resource Evaluation and Simulation System) (Clark et al., 2002) was used because of its ability to determine the long-term average flow of water from reservoirs, stormwater reuse schemes, rainwater tanks and desalination plants. If the selected sequence does not satisfy future demand, another preliminary plan needs to be developed by selecting another combination of water supply options to meet demand. For a satisfactory sequence plan, the total supply from each of the selected water supply options needs to be calculated in order to determine values for all of the selected sustainability objectives, including the objective that is optimized as part of the sequencing process (i.e. economic cost for the Adelaide case study), as well as all of the other objectives (i.e. greenhouse gas emissions for the Adelaide case study). The result of the process is a heuristic optimal sequence plan. It should be noted that the sequencing approach is adaptive, 
Beh et al., Sequencing of water supply options at the regional scale incorporating sustainability objectives

allowing long term plans to be reviewed periodically (e.g. 5 to 10 years) to take account of

changes in circumstances and new information.

\section{RESULTS AND DISCUSSION}

The unit objective function values obtained by implementing the process outlined in Error! Reference source not found. are presented in Figure 5. As can be seen, Happy Valley Reservoir, Myponga Reservoir and the River Murray transfer offer both low cost and low GHG emissions; rainwater tanks have a higher unit cost but a lower unit GHG emission in comparison to desalination; and stormwater reuse schemes fall in-between the other options. However, it should be noted that the estimated cost of stormwater reuse schemes does not include allowances for land acquisition and distribution networks.

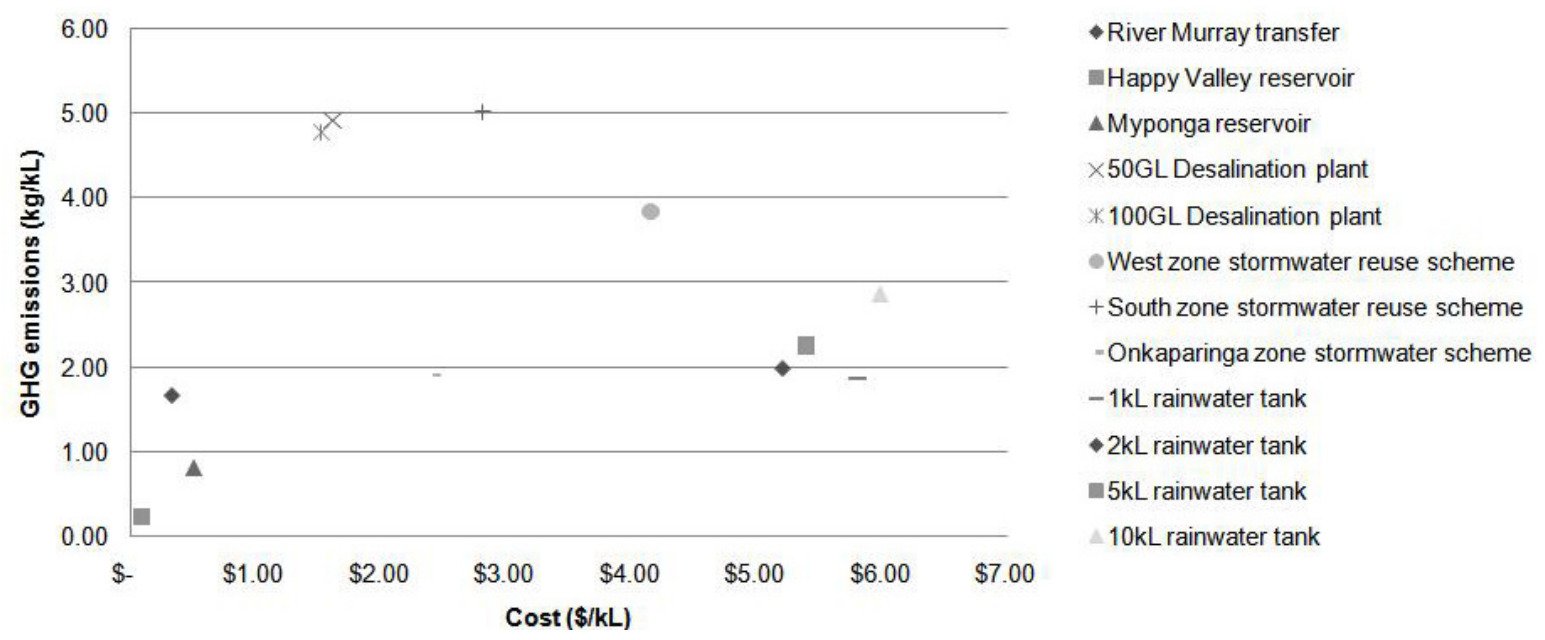

Figure 5 Unit trade-off of potential water supply options

The optimal cost sequence obtained for the case study is shown in Figure 6. Happy Valley Reservoir, Myponga Reservoir and transfer from the River Murray were the supply options included at the first decision stage, since these options have the lowest unit cost. However, the combination of these options proved insufficient to meet the demand for the next five years. Therefore, various stormwater reuse schemes were also included, which have a lower cost than either rainwater tanks or the desalination plant. The West zone stormwater scheme was not considered due to its limited yield, even though it has a lower unit cost than the South zone and Onkaparinga zone stormwater schemes.

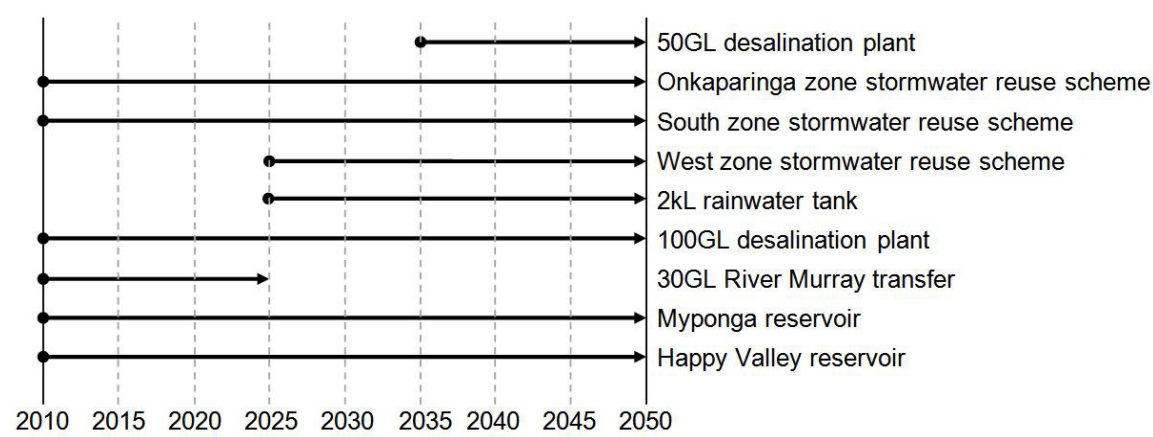

Figure 6 Heuristic optimal sequence plan

As mentioned previously, from 2025, supply from the River Murray was terminated in the system. To compensate for this loss of supply, $2 \mathrm{~kL}$ rainwater tanks and the reuse of West zone stormwater were then introduced during the fourth decision stage, before the 50GL desalination plant was introduced in 2035. The present value of the water supply options in the final sequence plan was \$1,914 million, with GHG emissions of 12.59 million tonnes. 
Beh et al., Sequencing of water supply options at the regional scale incorporating sustainability objectives

\section{CONCLUSIONS AND RECOMMENDATIONS}

The novel sequencing approach proposed in this paper incorporates sustainability objectives into the sequencing of water supply projects at the regional scale, as well as consideration of various potential water supply options, such traditional surface water resources, desalination and water re-use. Additionally, the proposed approach allows long term plans to be reviewed at regular intervals to take account of changes in circumstances. The approach was tested using the case of the southern Adelaide supply system over a planning horizon of 40 years and a sequence plan that was optimised for cost was generated. In addition, the GHG emissions of the least-cost sequence were also calculated. The resulting sequence plan included a mixture of reservoirs, stormwater schemes, rainwater tanks and desalinated water at a total cost of \$1,914 million with associated GHG emissions of 12.59 million tonnes.

\section{ACKNOWLEDGEMENTS}

The authors would like to thank David Cresswell and Richard Clark, who developed the WaterCress simulation model for their technical assistance. In terms of obtaining information for the southern Adelaide water supply system, we would like to acknowledge Alan Collett from SAWater. In addition, the authors would like to thank Barbara Brougham for her editorial assistance with this paper.

\section{REFERENCES}

Becker, L. and Yeh W.WG. (1974). Optimal timing, sequencing and sizing of multiple reservoir Surface water supply facilities, Water Resources Research, 10(1), 57-62.

Braga, B., Conejo J., Becker L. and Yeh W. (1985). Capacity Expansion of Sao Paulo Water Supply, Journal of Water Resources Planning and Management, Vol. 111, No. 2.

Chartres, C. and Williams J. (2006). Can Australia overcome its water scarcity problems? Journal of Developments in Sustainable Agriculture, Vol 1, 17-24.

Clark, R., Pezzaniti D. and Cresswell D. (2002). Watercress - Community Resource Evaluation and Simulation System - A tool for innovative urban water system planning and design, Proc Hydrology and Water Resources Symposium, Melbourne, 20-23 May 2002.

Coombes, P.J. and Lucas S. (2006). Towards sustainable water strategies in the Perth region of Western Australia: Inclusion of decentralized options. $1^{\text {st }}$ National HYDROPOLIS Conference, Perth, Western Australia, 2006.

Dandy, G.C. and Connarty M.C. (1994). Interactios between water pricing, demand management and the sequencing of water resource projects. In: Water Down Under 94: Groundwater/Surface Hydrology Common Interest Papers; Preprints of Papers. Barton, ACT: Institution of Engineers, Australia, 1994, 219-224.

Department of Water, Land and Biodiversity, 2009, Water for Good, Government of South Australia, viewed 22 July $2010,<$ http://www.waterforgood.sa.gov.au $>$.

Eroksuz, E. and Rahman A. (2010), Rainwater tanks in multi-unit buildings: A case study for three Australian cities. Resources, Conservation and Recycling. 54(2010), 1449-1452.

Gleick, P.H. (1998). Water in crisis: paths to sustainable water use. Ecological Applications, 8(3), pp. 571-579.

Paton, F.L., Baulis J.P., Staniford B.S., Maier H.R. and Dandy G.C. (2009). Considering sustainability in the Planning and management of regional urban water supply systems: A case study of Adelaide's Southern system. $18^{\text {th }}$ World IMACS/MODSIM Congress, Cairns, Australia, July 2009, 3357-3363.

Voivontas, D., Arampatzis G., Manoli E., Karavitis D. and Assimacopoulos, D. (2003) Water supply modeling towards sustainable environmental management in small islands: the case of Paros, Greece, Desalination, 156(1-3), 127-135. 